\title{
A DIDÁTICA NA PERSPECTIVA MULTI/INTERCULTURAL EM AÇÃO: CONSTRUINDO UMA PROPOSTA
}

\author{
VERA MARIA CANDAU \\ Departamento de Educação da Pontifícia Universidade Católica do Rio de Janeiro \\ vmfc@edu.puc-rio.br.
}

\section{MIRIAM SOARES LEITE}

Doutoranda do Programa de Pós-Graduação em Educação

da Pontifícia Universidade Católica do Rio de Janeiro

miriamsleite@yahoo.com.br.

\section{RESUMO}

Este trabalho se situa no contexto da pesquisa Ressignificando a Didática na Perspectiva Multi/ Intercultural, realizada com o apoio do Conselho Nacional de Pesquisas Tecnológicas, no período de 2003 a 2006. Teve por principal objetivo construir e desenvolver, em caráter exploratório, um curso de Didática dirigido à licenciatura em Pedagogia, na perspectiva multi/intercultural, com abordagem metodológica inspirada na pesquisa-ação. A experiência desenvolveu-se durante um semestre letivo e foi realizada pela equipe do Grupo de Pesquisas sobre Cotidiano Escolar, Educação e Cultura(s), composta por dez integrantes. Apoiou-se em ampla literatura sobre a temática, que vem sendo explorada pelo grupo desde 1996. Após descrição e análise do desenvolvimento do curso, são levantados questionamentos, tensões e desafios para a incorporação da interculturalidade nas práticas educativas, em torno dos seguintes eixos: múltiplas narrativas, alteridade e estranhamento, e desconstrução e resistência. Conclui reafirmando a relevância da temática abordada e a complexidade da proposta em discussão.

DIDÁTICA - FORMAÇÃO DE PROFESSORES - INTERCULTURAL - PESQUISA-AÇÃO

\footnotetext{
Este trabalho se insere em projeto que estamos desenvolvendo no Grupo de Estudos sobre Cotidiano, Educação e Cultura(s) - Gecec -, vinculado ao Departamento de Educação da Pontifícia Universidade Católica - PUC-Rio. Desde 1996, trabalhamos numa linha de pesquisas cujo objeto central tem sido o estudo das relações entre educação e cultura(s) em diferentes espaços educativos, tendo por principal finalidade contribuir para o aprofundamento desta problemática e oferecer elementos para que as práticas pedagógico-didáticas possam ser repensadas e/ou reinventadas, incorporando, de maneira crítica, a questão das diferenças culturais na pluralidade de suas manifestações e dimensões.
} 


\section{ABSTRACT}

DIDACTICS WITHIN THE MULTI/INTERCULTURAL PERSPECTIVE: DEVELOPING A PROPOSAL. This article arises from the 2003-2006 research project "Assigning a New Concept to Instruction, with a Multi/Intercultural Approach", sponsored by the National Council for Research of Brazil. The main goal was to develop and implement an undergraduate instruction course, of an exploratory nature and with a multi/intercultural perspective, inspired on the action-research approach. Ten members of The School Daily Routine Education and Culture Research Group, conducted the research, which lasted one school semester. A broad bibliography, compiled since 1996, was consulted. After a basic description and review of the course, difficulties and challenges regarding the approach are discussed, centering on the following issues: multiple narratives, alterity versus strangement and deconstruction versus resistance. As a conclusion, it was stressed the relevance as well as the complexity of this proposal.

DIDACTS - TEACHERS EDUCATION - INTERCULTURAL - ACTION-RESEARCH

Este artigo se situa no contexto da pesquisa Ressignificando a Didática na Perspectiva Multi/Intercultural, realizada com o apoio do CNPq, no período de 2003 a 2006. A investigação representou um importante marco na trajetória que vimos realizando, pelo caráter propositivo que conferiu ao nosso trabalho. As pesquisas anteriores, desenvolvidas pelo grupo de pesquisa, haviam articulado, em diferentes contextos educativos e valendo-se de estratégias diversificadas, levantamentos bibliográficos e pesquisas empíricas, buscando, entre outros objetivos, mapear a penetração da perspectiva multi/ intercultural' na prática e na produção teórica do campo educacional. Em termos gerais, ficou evidente, nessas investigações, não somente a ausência de tal perspectiva nas práticas pedagógicas observadas, como também sua frágil incorporação nos discursos dos sujeitos envolvidos e na produção teórica do campo. Tornava-se clara, dessa forma, a importância da continuidade dos estudos teóricos, mas também a urgência de se focalizarem as práticas pedagógicas.

A partir dessa percepção, definimos as questões norteadoras da pesquisa, que impuseram a necessidade do desenvolvimento, em caráter exploratório, de um curso de Didática, cujo eixo articulador fosse a perspectiva multi/in-

I. Entendemos o multiculturalismo como uma abordagem das relações entre os diferentes grupos culturais nas sociedades atuais, que abriga no seu interior diferentes perspectivas, entre as quais a intercultural. 
tercultural: "Que elementos básicos devem ser considerados na realização de um processo de ressignificação da Didática nesta perspectiva? Como trabalhálos nos cursos de Didática na formação inicial e continuada de professores?".

A revisão bibliográfica empreendida na primeira etapa desta pesquisa veio confirmar a pertinência dessas questões. Não apenas pôde-se perceber que a perspectiva multi/intercultural permanece pouco presente na produção teórica do campo da Didática, mas também que essa presença tende a se limitar à abordagem de questões mais amplas, não chegando a se ocupar das temáticas relativas ao dia-a-dia escolar. Nas entrevistas com especialistas da área, realizadas na segunda etapa da pesquisa, manifestou-se o questionamento da aplicabilidade de tais teorizações nas práticas do cotidiano da sala de aula.

\section{A ABORDAGEM DA PESQUISA-AÇÃO: UMA INSPIRAÇÃO}

Ainda na fase de construção do projeto da pesquisa, acenamos, com algum cuidado, para a modalidade da pesquisa-ação como um formato inspirador para a busca de encaminhamentos para essas questões. De fato, diversos são os entendimentos e as possibilidades de implementação desse tipo de investigação, e o desenvolvimento da pesquisa confirmou a adequação desse cuidado inicial.

Segundo Michel Thiollent ( 1985), autor considerado de especial relevância para a discussão desse tema no campo educacional:

Entre as diversas definições possíveis, daremos a seguinte: a pesquisa-ação é um tipo de pesquisa social com base empírica que é concebida e realizada em estreita associação com uma ação ou com a resolução de um problema coletivo e no qual os pesquisadores e os participantes representativos da situação ou do problema estão envolvidos de modo cooperativo ou participativo. (p. I4, grifo nosso)

Também René Barbier, em publicação mais recente (2004), nos lembra da diversidade de práticas investigativas abrigadas sob o rótulo genérico de pesquisa-ação. Inicia sua reflexão definindo a pesquisa-ação conforme proposta pelo Institut National de Recherche Pédagogique: "Trata-se de pesquisas nas 
quais há uma ação deliberada de transformação da realidade; pesquisas que possuem um duplo objetivo: transformar a realidade e produzir conhecimentos relativos a essas transformações" (p. I7). Apresenta, no mesmo texto, sua própria visão dessa modalidade de pesquisa, em que enfatiza, ainda mais que Thiollent, a necessidade de "implicação" de todas/os as/os que nela estão envolvidas/os. Propõe, inclusive, uma escrita coletiva dos resultados do trabalho e o compartilhamento dos cadernos de campo.

Não chegamos a tanto. Nosso trabalho promoveu apenas de forma limitada o engajamento de uma parcela significativa dos sujeitos envolvidos na pesquisa: as alunas da turma em que foi desenvolvido o curso de Didática aqui em discussão. Obviamente informadas a respeito da investigação em andamento, tiveram uma participação mais direta nos momentos de avaliação do curso, que foram promovidos ao longo do semestre letivo. Além disso, sua atuação cotidiana nas aulas também resultava em intervenção nos rumos da pesquisa, uma vez que, no decorrer do curso, a equipe da pesquisa se reuniu semanalmente para analisar e repensar o andamento do trabalho, discutindo de forma sistemática, com base nos registros dos cadernos de campo das pesquisadoras, as questões suscitadas e os dados que emergiam da dinâmica desencadeada. Consideramos ainda que houve de fato "implicação" da equipe de pesquisa, na medida em que assumimos uma posição de autoria coletiva, desde a concepção do curso até o relatório final, respeitadas as particularidades pessoais e de trajetória acadêmico-profissional de cada participante.

Diante de tais considerações, reafirmamos que a perspectiva da pesquisa-ação foi assumida como uma inspiração metodológica para o trabalho. Convém também ressaltar que os objetivos de transformação da realidade e de produção de conhecimentos, característicos dessa metodologia, nortearam o desenvolvimento dessa etapa da pesquisa.

\section{PLANEJAR NO COLETIVO: VISÕES, DIÁLOGOS, NOVAS VISÕES}

○ curso de Didática para a licenciatura em Pedagogia, foi construído, basicamente, em cinco momentos.

A diversidade de trajetórias - tanto no sentido pessoal, como no de atuação acadêmico-profissional -, trazida pelas participantes da pesquisa, proporcionou uma variedade de pontos de vista que pôde enriquecer os debates de 
planejamento e avaliação da experiência: contávamos com doutoras, doutorandas, uma pós-doutoranda, mestras, uma mestranda e alunas da graduação, de diferentes faixas etárias, com experiências variadas no ensino e na reflexão sobre a Didática como professoras e/ou como alunas. Assim, as dinâmicas iniciais do planejamento cumpriram o papel de integração do grupo, na medida em que possibilitaram esclarecimentos, posicionamentos e a definição de mínimos comuns que viabilizassem o trabalho coletivo.

A primeira dessas dinâmicas foi uma tempestade cerebral, que permitiu a emergência de questionamentos que acompanhariam nossas reflexões ao longo de toda a experiência.

Um primeiro debate já se anunciava nas entrevistas que havíamos realizado com protagonistas representativas/os do cenário da Didática no Brasil, em etapa anterior da pesquisa: se a questão da diferença não constitui preocupação inédita para as/os educadoras/es - tanto em termos teóricos, como na prática pedagógica - qual a especificidade da perspectiva multi/intercultural? Tínhamos como consenso a noção de que essa perspectiva se nos apresentava como uma ampliação e atualização da perspectiva crítica, mas qual o significado mais preciso de tal ampliação, especialmente no tocante às questões da diferença no cotidiano escolar?

Outra importante indagação surgida já nessas primeiras discussões de planejamento referiu-se às opções metodológicas do curso em construção: como a perspectiva multi/intercultural afetaria a organização e o encaminhamento das aulas em um curso de graduação? Que dinâmicas seriam mais coerentes e produtivas para um trabalho didático nessa perspectiva? Como avaliar? Como lidar com a questão da leitura acadêmica? Como pautar tais decisões no reconhecimento positivo da diferença, mas também na busca pela igualdade de direitos e oportunidades para todas?

Por fim, porém não com menor força, ocupamo-nos dos chamados temas "clássicos" da Didática: seriam mantidos como conteúdos do curso? Por quê? Que outros temas se colocam na atualidade para o estudo da Didática em nível de graduação? Os chamados temas "clássicos" deveriam ser substituídos por essas novas questões ou poderiam/deveriam coexistir curricularmente? Também importa registrar o questionamento da adjetivação "clássicos" para determinados assuntos desse campo: como se constroem os "clássicos"? Quem determina a inclusão e a exclusão de temas nessa categoria? 
Todas essas questões apontaram a necessidade daquela que se constituiu na segunda etapa do planejamento do curso: uma rodada de releituras que abordassem questões centrais do multi/interculturalismo na educação.

Foram discutidos, entre outros, textos de Barreiros (2005), Candau (2002, 2005), Gimeno Sacristán (2002), McLaren (2000), Perrenoud (2000), Stoer e Cortesão (1999). Com base nesses debates, pudemos começar a definir coletivamente algumas respostas iniciais aos questionamentos surgidos na primeira etapa do planejamento. A idéia era que essas proposições operassem como princípios que viriam pautar nosso trabalho - princípios que podem e devem mudar no confronto com a prática. Como não seria possível reproduzir aqui todos os aspectos tratados nas discussões, destacamos a seguir pontos que se fizeram mais presentes nos momentos posteriores do desenvolvimento do curso.

Stoer e Cortesão (1999) lembraram-nos mais uma vez do caráter monocultural em geral assumido pelas escolas e seus sujeitos, estes caracterizados pelo que os autores chamam de "daltonismo cultural", que os impediria de enxergar as diferenças culturais que colocariam tal modelo em questão. Defendem também a necessidade de desenvolvimento e aplicação no cotidiano escolar de "dispositivos de diferenciação pedagógica", assunto retomado quando da discussão do texto de Perrenoud (2000) sobre o tema. Este último texto tornou-se fundamental para a abordagem que pretendíamos priorizar no curso, como item curricular e como forma de lembrar, já no título, um desafio central para o trabalho que ora planejávamos: "conceber e fazer evoluir os dispositivos de diferenciação". Mais do que discutir com as alunas sobre essas idéias, elegemos tais formulações como eixos metodológicos importantes na orientação da nossa prática de sala de aula.

Além disso, foram também determinantes as seguintes reafirmações:

- o enfoque cultural impunha o reconhecimento da historicidade de todos os textos, contextos e sujeitos de que viéssemos a nos ocupar no planejamento e no desenvolvimento do curso;

- a atenção à diferença não deveria e não precisaria implicar um menor cuidado com as questões de desigualdade; tal afirmação, contudo, não significava negar a tensão que reside na articulação entre as bandeiras de igualdade e do reconhecimento da diferença no cotidiano 
das instituições de ensino, o que veio a ser confirmado no desenvolvimento da experiência;

- o eurocentrismo, ainda tão presente nas práticas e nos discursos do campo, precisaria ser desestabilizado, assim como deveríamos questionar a naturalização da "branquidade" e as perspectivas essencialistas;

- a sala de aula seria entendida como espaço de múltiplas narrativas, em que deveria predominar o diálogo e a troca de saberes;

- a priorização, entre outras, da discussão sobre a linguagem, para além da sua suposta função de representação da realidade;

- a valorização da oralidade das alunas, bem como de suas experiências e saberes, o que representaria um passo concreto em termos de metodologia didática voltada para as questões das diferenças culturais;

- a perspectiva do empoderamento, que deveria permear toda a nossa atuação no curso.

Ainda no âmbito das discussões provocadas por nossas leituras, retomamos a questão dos temas clássicos: permaneceriam inalterados? Por certo que não. Independentemente da nossa crítica ao termo "clássicos", reconhecemos a pertinência dessas temáticas para o dia-a-dia da escola. Em um dos textos debatidos, Barreiros (2005), remetendo-se a McLaren, defende que o "enfoque nas questões miúdas do cotidiano escolar não faz perder a dimensão política e mesmo social" (p.95). Concordamos com esses autores, destacando que o "como fazer" não nos leva, necessariamente, de volta à chamada didática instrumental e sua pretensa neutralidade técnica. Planejamento, metodologia, avaliação, disciplina, currículo e relação professor-aluno continuariam como conteúdos relevantes, porém, não exclusivos, tampouco nos seus formatos tradicionais. Colocava-se, para nós, o desafio de repensá-los na perspectiva multi/intercultural.

Outro importante questionamento feito nos nossos debates iniciais dizia respeito à metodologia a ser priorizada nas aulas do curso. Além das decisões metodológicas já apontadas, resolvemos optar pelo formato de oficinas²,

2. Concebemos as oficinas pedagógicas, de acordo com Gonzalez (apud Candau, 2000, p. I I 7) como: "um tempo-espaço para a vivência, a reflexão, a conceitualização; como síntese do 
dado o reconhecimento da necessidade de sensibilização para as questões que traríamos para a turma, e não apenas de informação.

Com menor aplicabilidade prática e imediata, rediscutimos outra das nossas primeiras indagações: tratar da diferença é novidade em educação? A esse respeito, Gimeno Sacristán (2002), um dos autores/as estudados/as, advertia: "convém não anunciar esses problemas como sendo novos, nem lançálos como moda, perdendo a memória e provocando descontinuidades nas lutas para mudar as escolas" (p. 15). Concordando com esse autor, alguns membros da equipe realizaram um estudo em que se buscou resgatar os sentidos da diferença para o pensamento pedagógico brasileiro. Concluem, no trabalho realizado, que a dimensão cultural, para além dos seus determinantes de classe social - ou seja, incluindo questões étnico-raciais, de gênero, de opção sexual, entre outras - desponta como importante especificidade da abordagem da problemática da diferença pela educação na perspectiva multi/intercultural, assim como o diálogo crítico com as contribuições do chamado pensamento pós-moderno ${ }^{3}$.

Chegávamos, desse modo, a um conjunto básico de princípios e objetivos que passaram a orientar nossas atividades de planejamento.

A etapa que se seguiu permitiu que confrontássemos tais princípios com questões mais concretas, como a definição dos conteúdos do curso. Surgia

pensar, sentir e agir. Como o lugar para a participação, a aprendizagem e a sistematização dos conhecimentos. [...] $\mathrm{Na}$ oficina, através do jogo recíproco dos participantes com as tarefas, confluem o pensamento, o sentimento e a ação. Em síntese, a oficina pode converter-se no lugar do vínculo, da participação, da comunicação e, finalmente, da produção social de objetos, acontecimentos e conhecimentos."

3. Para esclarecer quanto ao sentido que atribuímos, neste texto, à polêmica expressão "pensamento pós-moderno", reproduzimos aqui a definição proposta por Peter McLaren "Falando de uma forma ampla, a crítica pós-moderna caracteriza-se por uma rejeição ou uma denúncia das fundações epistêmicas do modernismo ou metanarrativas, ou ainda, da destituição da autoridade da ciência positivista que essencializa as diferenças entre o que parecem ser identidades autoconstituídas; também um ataque à noção de um objetivo unificado para a história e a desconstrução da magnífica fraude iluminista do ego autocontido, estável e autônomo que supostamente seria capaz de agir independentemente de sua própria história, suas próprias cadeias de construção de significado, situação cultural e lingüística e sua inscrição em discursos de gênero, classe, raça, entre outros" (McLaren, 2000, p.6I). Diferencia ainda o "pós-modernismo lúdico" (de Baudrillard, Lyotard, entre outros), abordagens que trabalham com as questões acima, sem comprometimento de transformação social, do "pós-modernismo de resistência ou crítico" (p.67-68). 
nesse ponto um complicador que nos acompanharia até o fim dessa experiência: o tempo do semestre letivo era relativamente curto - 60 horas-aula. Quando assumimos uma didática multidimensional, crítica e intercultural, percebemos a multiplicidade de aspectos dos processos de ensino-aprendizagem e seus contextos que demandam reflexão na formação de professoras/es. A seleção de temas a serem tratados no curso revelou-se complexa e se concluiu menos pela certeza das escolhas que realizamos do que pela necessidade de nos atermos ao calendário e às orientações normativas da universidade.

Mantivemos nossa decisão de organizar as aulas no formato de oficinas pedagógicas, visando garantir o trabalho de sensibilização para as questões que seriam discutidas e priorizar a dimensão prática dessas questões. Entendíamos, entre outros aspectos, que essa estruturação do trabalho pedagógico favoreceria a participação e a socialização da palavra na sala de aula, fundamentais para a conquista dos objetivos que havíamos definido. Operaríamos ainda com a noção de meta-aula, isto é, o formato da nossa aula já deveria constituir em si conteúdo daquele curso de Didática.

As decisões quanto à avaliação foram orientadas para atender aos princípios que defendíamos, mas também às exigências institucionais. Assim é que definimos, dentro dos padrões impostos pela universidade, uma composição de nota que consideraria a realização de tarefas semanais individuais, trabalhos individuais em sala de aula (com opção entre trabalho oral e escrito, com consulta, em dois momentos do semestre letivo, abordando os temas tratados até então) e auto-avaliação.

Por fim, estabelecemos como eixos para a elaboração das oficinas quatro linhas de ação que consideramos fundamentais para a promoção de uma educação multi/intercultural $\left.\right|^{4}$ :

- desconstruir: remete-se à questão dos preconceitos e da discriminação, buscando desnaturalizá-los e questionar o caráter monocultural e etnocêntrico da instituição escolar, nas diversas dimensões em que se manifesta no seu dia-a-dia;

4. Esses eixos de ação foram propostos inicialmente pela coordenadora do grupo de pesquisa, no $2^{\circ}$ Seminário Internacional sobre Educação Intercultural, Gênero e Movimentos Sociais, promovido pela Universidade Federal de Santa Catarina, em 2003. 
- articular: refere-se à tensão igualdade-diferença;

- resgatar: trata-se do resgate dos processos de construção das identidades culturais;

- promover: desmembra-se em outras ações: interação sistemática; enfoque global (ou seja, a perspectiva deve afetar todos os níveis da prática pedagógica); e empoderamento.

Iniciamos, então, a construção das oficinas, seguros da pertinência das nossas opções, mas também cientes de que haveria diversas outras possibilidades de encaminhamento igualmente interessantes para o curso que pretendíamos realizar. Conforme mencionado, essas oficinas foram elaboradas coletivamente pela equipe, ao longo do período letivo, alimentadas pelas contribuições das alunas e pela permanente análise e discussão do trabalho realizado.

O curso de Didática ficou, então, constituído pelas seguintes oficinas pedagógicas: $1^{a}$ ) Quem somos, nossas leituras do mundo e nossas buscas como educadores/as; 2 $2^{\mathrm{a}}$ ) Educação escolar ontem e hoje; $3^{\mathrm{a}}$ ) Do sonho de Comênio à perspectiva crítica; 4a) Didática e interculturalidade: ampliando a perspectiva crítica; $5^{a}$ ) Professores/as e alunos/as: sujeitos socioculturais; 6ª Cotidiano escolar: as múltiplas manifestações da diferença; $7^{\mathrm{a}}$ ) A sala de aula: encontros e desencontros; 8 $8^{\text {a }}$ Cotidiano escolar e educação em valores; 9a) Cotidiano escolar e cruzamento de saberes; $10^{\mathrm{a}}$ ) Planejamento didático e dispositivos de diferenciação pedagógica; I I ${ }^{\mathrm{a}}$ ) Avaliação e reconhecimento das diferenças; $12^{\mathrm{a}}$ ) Didática e perspectiva multi/intercultural.

\section{CONFRONTAR COM A PRÁTICA: ACERTOS, BUSCAS, NEGOCIAÇÕES}

O curso de Didática Geral que construímos foi implementado no segundo semestre de 2005, no curso de Pedagogia, com aulas semanais de duração de quatro horas cada. A concentração dos quatro tempos semanais em um único encontro decorreu da nossa opção pelo trabalho com oficinas pedagógicas, que avaliamos como mais bem realizadas quando não há interrupção entre os momentos que as constituem. Também em razão dessa escolha, tivemos de insistir junto à universidade para que nos fosse destinada uma sala espaçosa, que possibilitasse flexibilidade na organização espacial das alunas. 
A turma possuía 30 alunas inscritas (28 alunas e dois alunos) $)^{5}$, porém a freqüência mais habitual ${ }^{6}$ oscilou entre 20 e 25. Em geral, as estudantes estavam cursando o quarto período de créditos, e algumas (poucas) já atuavam como professoras. Mas todas tinham, ao menos, a experiência do estágio. Não precisamos fazer um levantamento mais sistemático para constatar a diversidade do grupo, que estava visível: havia negras, brancas, mestiças; cariocas, nordestinas, interioranas; bolsistas, não-bolsistas; moradoras da zona oeste, norte e sul da cidade; meninas solteiras, jovens mães, alunas que retomavam os estudos; leitoras experientes, leitoras aprendizes; tímidas, extrovertidas, participativas, desconfiadas, entediadas, entusiasmadas...

A participação das alunas, seu envolvimento, suas falas, produções, posturas, atitudes, enfim, tudo o que se passava em sala de aula e era registrado no caderno ou na memória das pesquisadoras foi considerado nessas discussões. Houve, entretanto, dois momentos em que convidamos as alunas a refletirem mais especificamente sobre a experiência do curso.

A primeira dessas avaliações ocorreu no final de setembro, quando já havíamos realizado seis oficinas. Elaboramos um documento simples, com três questões abertas, indagando sobre "aspectos do curso que você considerou mais significativos", "elementos de que você não gostou, considerou desnecessários, trabalhados de modo inadequado, entre outros motivos", e solicitamos a apresentação de "sugestões para o aperfeiçoamento do desenvolvimento do curso". Provavelmente devido ao fato de esse documento ter sido respondido em casa, individualmente, verificamos uma grande dispersão nas respostas.

Diversas sensibilidades já eram esperadas: era previsível, por exemplo, que algumas se queixassem do excesso de leitura, enquanto outras reclamassem por mais. Apenas mais uma manifestação da diferença com que temos de lidar no cotidiano da prática pedagógica. Mas a multiplicidade de aspectos le-

5. Por uma questão de coerência, estaremos generalizando pelo feminino quando falarmos da turma, subvertendo a tradição lingüística que privilegia o gênero masculino para se referir a coletivos, mesmo quando estes apresentam uma composição majoritariamente feminina, como nesse caso.

6. Ao longo do semestre letivo, um aluno e duas alunas trancaram a matrícula e duas outras foram reprovadas por freqüência. 
vantados pela turma comprometia nossas tentativas de organização dos dados, o que nos levou a proporcionar ao grupo uma oportunidade de amadurecimento dessa reflexão.

Reformulamos, então, o cronograma e criamos uma oficina não prevista no planejamento inicial - Uma parada no caminho - em que promoveríamos uma discussão coletiva para avaliação do curso. Além disso, ao discutir a avaliação das alunas, havíamos percebido que a opção pela metodologia de oficinas não estava clara para uma parte da turma, o que indicou a necessidade de aprofundamento e discussão sobre essa estratégia didática, que incluímos na programação desse encontro.

$\mathrm{Na}$ nova rodada de avaliações, as oficinas foram apontadas como um acerto do curso, assim como se destacaram: as dinâmicas utilizadas, por favorecerem a interação entre as alunas; a ênfase na relação teoria-prática, ao tratar das questões do cotidiano escolar; e a valorização da palavra da aluna. Mais estudos de caso foram sugeridos, e o tempo apareceu como um grande vilão do nosso trabalho: algumas exposições foram consideradas apressadas, textos pouco explorados, o excesso de informação, de leituras e de trabalhos foi criticado.

Discutindo nossa atuação, concluímos pela necessidade de mais tempo para a realização do trabalho que pretendíamos, não de menos conteúdo, leituras ou atividades. Entretanto, o tempo não se apresentava como um componente flexível do planejamento, e tivemos de rever alguns aspectos das nossas estratégias.

O formato oficina foi reconfigurado, uma vez que passamos a prever um momento no início da aula para discussão das leituras indicadas (referentes à temática tratada na oficina anterior), antes da atividade de sensibilização da oficina do dia. Passamos também a evitar exposições de conteúdo relevante no final do encontro, dado que várias alunas tinham de sair antes do final da aula, devido a compromissos de trabalho, e que as que permaneciam demonstravam cansaço.

A segunda avaliação realizada pelas alunas novamente apresentou características dispersivas, não tendo havido, porém, condições objetivas de avançar coletivamente na reflexão, devido ao fim do semestre letivo. De todo modo, a metodologia foi mais uma vez apontada como um ganho do curso por diversas alunas, e a pertinência da perspectiva multi/intercultural como eixo articu- 
lador da disciplina representou a única unanimidade na turma. Entretanto, duas alunas que concordaram com a pertinência do enfoque julgaram excessiva a ênfase na problemática da diferença, contrastando com a posição do restante da turma. De modo similar, as oficinas, valorizadas positivamente por um grande número de alunas, também foram alvo de críticas. Independentemente da representatividade quantitativa, todas as ponderações foram discutidas na nossa própria avaliação e análise do curso.

Para orientar a reflexão da equipe de pesquisa acerca da experiência do curso, retomamos os questionamentos, decisões e princípios afirmados nas discussões de planejamento. Desse modo, organizamos nossas análises em torno dos eixos propostos para nossa atuação pedagógica: desconstruir, articular, resgatar, promover.

Conforme mencionado, a ação de desconstruir volta-se contra as diversas formas de preconceito e de discriminação naturalizadas nas práticas e discursos da sociedade. Essa proposta de ação desdobrou-se em opções metodológicas e perpassou os temas abordados no curso. Assim, questionamos o tradicional preconceito acadêmico que desvaloriza as experiências e os saberes das alunas oriundas das classes populares, quando estruturamos nossos encontros de modo a favorecer espaço, sentido e valor para todas as vozes presentes na turma. Buscamos também desestabilizar a naturalização do caráter monocultural da escola, discutindo sobre: concepções de cultura; a crítica do multi/interculturalismo à pretensão homogeneizadora das instituições escolares; as várias dimensões da diferença e a multiplicidade das suas manifestações nos espaços educativos; professor/a e aluno/a como sujeitos socioculturais; questões acerca da seleção de conteúdos, saberes e valores, linguagem e comunicação, expectativa do/a professor/a, preconceito e discriminação no cotidiano escolar. Nessas discussões, evidenciou-se a tensão entre a concepção socioistórica de cultura, que orientava nosso curso, e a tradição de verdades universais e aistóricas que informavam, com freqüência, posicionamentos de nossas alunas.

O segundo eixo de ação mobilizou bastante o grupo nesse momento: até que ponto conseguimos articular questões de igualdade e de diferença?

Quanto à inclusão dessa discussão nos temas de estudo e debate do curso, não houve dúvidas: foi abordada quando tratamos das contribuições, para a educação, do multi/interculturalismo, "identificando questões concretas que 
desafiam esta articulação na sociedade e na escola"7; ao buscarmos "articular a vivência da igualdade com a vivência da diferença, nos espaços escolares freqüentados" 8 ; em exercícios de memória da vida escolar; ao estudarmos as "diferentes abordagens da questão da diferença pelo pensamento pedagógico brasileiro"; quando debatemos "sobre questões de linguagem e de comunicação entre alunas/os e professores/as, freqüentes no dia-a-dia da escola" I0; entrevistando professoras; pensando o planejamento (décima oficina) e a avaliação ( I | ${ }^{a}$ oficina) nessa perspectiva. Essa articulação/tensão foi, portanto, uma temática debatida de forma relativamente ampla no curso. Mas e quanto à turma, quanto a essa prática em sala de aula?

De fato, o curso foi concebido para uma coletividade - e não acreditamos que poderia ou deveria ter sido diferente. Partindo do reconhecimento de que o ensino individualizado não constituiria resposta eficaz para as situações de tensão entre as questões de diferença e de igualdade que emergiram no dia-a-dia do curso, identificamos, nas opções metodológicas descritas a seguir, nossos principais movimentos no sentido da articulação discutida:

- diversificamos os materiais didáticos utilizados e as dinâmicas de trabalho nas oficinas;

- em todos os encontros, promovemos trabalhos em grupo, buscando favorecer as trocas interpares, riqueza potencial da heterogeneidade perceptível na turma;

- procuramos criar espaços (relativamente) livres para a fala das alunas e valorizar suas diferentes contribuições, de forma a não hierarquizá-las;

- semanalmente, foram solicitados trabalhos escritos, de natureza variada, que recebiam análise individualizada por parte da coordenadora do curso.

Apesar desses esforços - que por certo nos aproximaram das nossas intenções de articulação do reconhecimento e valorização das diferenças com

7. Este foi um dos objetivos da primeira oficina: Quem somos, nossas leituras do mundo e nossas buscas como educadores/as.

8. Este foi um dos objetivos da segunda oficina: Educação escolar ontem e hoje.

9. Este foi um dos objetivos da sétima oficina: A sala de aula: encontros e desencontros.

10. Idem. 
a busca pela igualdade de direitos e oportunidades para todas - avaliamos que ainda há muito que avançar na prática e na teoria didática nesse sentido.

A ação de resgatar suscitou menor polêmica, e fomos unânimes no entendimento de um relativo sucesso nesse eixo de ação. Ao longo de todo o curso, trabalhamos com histórias de vida das alunas, em dinâmicas diversas na sala de aula, quando as interrogávamos a respeito de experiências pessoais entre outras razões, por reconhecermos a importância da narrativa autobiográfica nos (permanentes) processos de construção identitária. Mas também nos ocupamos de outras narrativas, como de professoras, de ex-alunas da graduação (por meio de palestras e entrevistas) e de pessoas dos círculos de relações das estudantes (quando solicitamos a investigação da vida escolar de outras gerações). A crítica a qualquer forma de essencialismo permeou todas essas discussões, e o aspecto de construção socioistórica das identidades culturais, assim como seu caráter fragmentário, híbrido e multifacetado, foram temas centrais de uma das oficinas"l.

Também o último eixo de ação analisado, pareceu-nos ter logrado efetivação. Promover desmembrava-se em outras três linhas de ação:

- interação sistemática: promovida nos constantes debates em plenária e, principalmente, nos trabalhos em grupo, cuja composição, na maior parte da vezes, foi aleatória;

- enfoque global: ou seja, a perspectiva de afetar todos os níveis da prática pedagógica, o que buscamos concretizar nas opções metodológicas já apresentadas; destaque-se o processo de avaliação, que incluiu a auto-avaliação, a possibilidade de trabalho individual oral e o retorno constante e individualizado para as produções semanais solicitadas às alunas;

- empoderamento: acreditamos que a valorização das experiências de vida das alunas e da sua participação oral, já referida algumas vezes neste relato, atuou positivamente nesse sentido; percebemos, inclusive, que essa participação se ampliou ao longo do semestre letivo, possivelmente devido a tais práticas; além disso, duas visitas de exalunas também colaboraram para a realização desse nível de ação -

11. Trata-se da quinta oficina. 
uma delas relatou sua experiência como bolsista de intercâmbio na Universidade Autônoma de Madrid, na Espanha, e a outra, formada pela instituição havia pouco tempo, contou da sua experiência como professora de um colégio bastante reconhecido na cidade; lembramos, ainda, a possibilidade de estudar e de produzir em sala de aula, o que viabilizou um melhor aproveitamento do curso para as muitas alunas que têm menor condição de dedicação aos estudos fora desse espaço (por compromissos familiares ou de trabalho).

O tempo, de fato, apresentou-se como fator complicador na realização de nossos planos e intenções: precisaríamos de mais tempo para poder abordar temáticas relevantes que não puderam ser incluídas no nosso programa, para aprofundar um pouco mais as que foram tocadas, para criar mais espaço de participação e aprendizagem para todas as alunas. Ainda assim, além dos ganhos já apontados neste relato, identificamos avanços na questão da relação teoria-prática - tanto no sentido dos temas tratados, como no da nossa própria atuação - e na articulação das questões do cotidiano escolar com discussões mais amplas da sociedade em geral.

\section{CONSTRUIR A PERSPECTIVA MULTI/INTERCULTURAL NA DIDÁTICA: TENSÕES E DESAFIOS}

Neste item, tendo sempre como foco central a ressignificação da Didática - concepção, conteúdo, tratamento dos diferentes temas e estratégias - a partir da perspectiva multi/intercultural, no horizonte da formação de professoras/es, conforme proposto no projeto de pesquisa, destacamos pontos de tensão e desafios identificados na experiência objeto deste artigo. São questões que convidam para aprofundamento, tanto por sua complexidade, como pela urgência com que demandam resposta nas salas de aula de todos os níveis de ensino.

\section{Múltiplas narrativas}

Ao afirmarmos a sala de aula multi/intercultural como espaço de múltiplas narrativas - ou seja, de narrativas e de contranarrativas, que se confron- 
tam em multidireções contingentes - estávamos assumindo uma perspectiva dialógica em termos metodológicos, mas também nos níveis epistemológicos e políticos da prática pedagógica. Várias tensões decorrentes da proposta de promoção do diálogo intercultural sistemático, em um curso de formação de educadoras/es vieram à tona.

O primeiro nível de tensão que destacamos pode ser exemplificado pelo relato que se segue, extraído do caderno de campo de uma das pesquisadoras:

Quando a discussão do texto Pedagogias críticas: ontem e hoje foi mencionada, a aluna Margarida ${ }^{12}$ destacou a questão do distanciamento entre teoria e prática na perspectiva crítica como o traço mais marcante dessa abordagem; ponderei que esse seria de fato um traço, porém não necessariamente o mais marcante [...] Iniciou-se, então, um debate (breve) sobre a relação entre teoria e prática, com Margarida reivindicando mais 'prática' no curso e Violeta mais teoria, esta última advertindo para o perigo de que essa preocupação com a prática se traduzisse em encontros para relato de experiências, no sentido de 'contação de casos', sem discussão teórica. Tentamos afirmar nossa preocupação em trazer a teoria sempre articulada com a prática e esclarecemos que as primeiras oficinas tinham, entre outros, o objetivo de situar o nosso curso dentro de um quadro mais geral da Pedagogia, principalmente por não querermos apresentar nossas posições e perspectivas como as únicas possíveis.

Nossa leitura desse questionamento desloca seu foco para a discussão do papel dos diferentes saberes socialmente disponíveis na formação universitária e mesmo escolar, não se detendo propriamente na relação teoria-prática em educação, que motivara inicialmente o debate relatado. Quanto a esta última, desde o início do planejamento do curso, tivemos clareza da necessidade de articulação permanente entre esses dois níveis de intervenção nos processos de ensino-aprendizagem de que tratávamos. $\bigcirc$ convite à fala das alunas foi uma das estratégias utilizadas para esse fim, mas não tinha apenas esse propósito, atendendo também à nossa opção pela valorização dos saberes e experiências trazidos pelas estudantes, e criticada pela aluna Violeta como espa-

12. Todos os nomes das alunas referidas neste texto são fictícios. 
ço para "contação de casos"' 13 . Entendíamos, como Pérez Gómez propõe, a sala de aula como um espaço privilegiado para o cruzamento de culturas:

O responsável definitivo da natureza, do sentido e da consistência do que os alunos e as alunas aprendem em sua vida escolar é este vivo, fluido e complexo cruzamento de culturas que se produz na escola, entre as propostas da cultura crítica, alojada nas disciplinas científicas, artísticas e filosóficas; as determinações da cultura acadêmica, refletida nas definições que constituem o currículo; os influxos da cultura social, constituída pelos valores hegemônicos do cenário social; as pressões do cotidiano, da cultura institucional, presente nos papéis, nas normas, nas rotinas e nos ritos próprios da escola como instituição específica; e as características da cultura experencial, adquirida individualmente pelo aluno através da experiência nos intercâmbios espontâneos com seu meio. (200 I , p. I)

Sem negar a importância da contribuição das ciências pedagógicas para a reflexão sobre as questões didáticas, procurávamos, tanto quanto possível, questionar a hierarquização dos saberes presentes nas nossas aulas, tentando promover o confronto entre as muitas visões que se ocupam do cotidiano escolar, o que incluiu a produção teórica reconhecida nesse campo científico, mas também a vivência de todas as envolvidas naquele processo de reflexão.

Os depoimentos das alunas eram sistematicamente trabalhados pelas coordenadoras das oficinas, que faziam dialogar essas falas com as proposições teóricas das/os autoras/es estudadas/os pela turma e também com outras trazidas na bagagem da sua formação. Possivelmente, o não-reconhecimento do diálogo com a teoria no formato que propusemos tenha se devido a dificuldades de valorização dos saberes da experiência.

Um outro aspecto dessa opção também nos parece desvalorizado em tal crítica: o papel da narrativa na constituição das identidades. Concordando com McLaren:

Nossas subjetividades precisam ser inscritas ou codificadas por meio de narrativas para que possamos agir. Estas podem ser contra-narrativas ou narrativas de

13. Esta interpretação do entendimento da aluna foi confirmada em outras situações do curso, em que ela se manifestou explicitamente nesse sentido. 
resistência ou narrativas forjadas no projeto autoritário do império e do colonialismo; a questão é que nossas identidades ganham forma com a contingência discursiva dos fechamentos arbitrários (mas incompletos) de significado, dentro do texto maior da memória histórica. (2000, p. 177-178)

Ao promover um espaço para o diálogo entre as muitas narrativas que eram trazidas pelas alunas, pretendíamos também intervir nas identidades profissionais que ali se construíam, desestabilizando "narrativas imperiais e autoritárias da sociedade" (McLaren, p. I65) naturalizadas na linguagem e nos nossos esquemas mentais de crítica e de análise social.

Entretanto, é sabido que a sala de aula não acontece em um vácuo histórico e político. É um espaço carregado de significados, que impõe relações assimétricas de poder, tanto entre professor/a e aluno/a, como entre os/as próprios/as alunos/as. O lugar do/a professor/a traz a autoridade do conhecimento suposto, mas também o poder bastante objetivo da aprovação e da reprovação, da proposta para bolsa de iniciação científica, do convite para o trabalho remunerado. Tampouco podemos supor horizontalidade entre as vozes discentes. Linguagem, objetos, gestos, roupas e postura de cada um/uma são textos cuja leitura não acontece de forma explícita, mas que apontam lugares de poder marcados socialmente para seus/suas portadores/as. A pesquisa anterior desenvolvida pelo grupo - Universidade, Diversidade Cultural e Formação de Professores - já identificara um freqüente sentimento de inadaptação por parte de estudantes bolsistas, quando oriundos/as de grupos sociais tradicionalmente excluídos desse nível de ensino. Na sala de aula, esse sentimento muitas vezes pode ter se traduzido em silêncio, com prejuízo de uma participação mais direta e mais construtiva para todas.

Tal desigualdade foi assinalada diversas vezes nos registros de observação das pesquisadoras. Fica evidente, na leitura desses relatos, que também nesse curso algumas alunas se apropriaram desse espaço de fala pública com maior domínio do que outras. Encontramos igualmente registros em que se assinala o progressivo crescimento da participação de alunas que no início do curso manifestavam comportamentos de pouco envolvimento e maior reserva. Ou seja, no cotidiano da prática pedagógica, em qualquer nível de ensino, lidamos com jogos de poder, cujas regras transcendem o espaço da sala de aula e não são simples de ser transformadas, dada a solidez e complexidade das suas 
construções. Entretanto, as várias estratégias que utilizamos no confronto com esses jogos trouxeram resultados: avaliamos que avançamos concretamente na direção de um ambiente de comunicação mais democrático.

Outro importante aspecto da opção pela multiplicidade narrativa na sala de aula é também referido no registro de observação: o fato de não querermos "apresentar nossas posições e perspectivas como as únicas possíveis". Quando localizamos historicamente a produção de tais perspectivas e trazemos vozes teóricas discordantes, favorecemos a construção da autonomia intelectual das alunas e reafirmamos o espaço de ensino-aprendizagem como o lugar da troca e do diálogo. Mais uma vez, entretanto, percebemos limites na efetivação das nossas intenções e propostas. Também nesse sentido pesa o lugar de poder do/a professor/a: não omitimos nossas posições, que podem ter sido traduzidas para muitas, pela força do hábito escolar, como o correto a ser aprendido. Para tanto, colaboram, não apenas tais hábitos, como também questões mais contingentes. Não há tempo para se explorarem de forma equânime as diferentes posições e tendências do pensamento pedagógico em um semestre letivo. Nossa parcialidade (explícita) também se fazia presente nos temas e autoras/es privilegiadas/os para estudo e discussão, comprometendo qualquer pretensão de acesso igualitário às muitas possibilidades de se pensarem as questões pedagógicas. Assim como em relação à questão do poder das várias vozes presentes na sala de aula, as diversas abordagens teóricas existentes para as questões discutidas - que constituiriam outro importante nível de multiplicidade narrativa - foram contempladas parcialmente.

\section{Alteridade e estranhamento}

A discussão da possibilidade de multiplicação das vozes legitimadas no contexto da aula universitária está bastante próxima das questões da alteridade que pudemos identificar nesse espaço. Os jogos de poder a que nos referimos estão permeados por tensões que marcam nossas relações com o outro.

Nas anotações referentes à primeira oficina, todas as pesquisadoras registraram a dificuldade de se lidar com a diferença, explicitamente manifesta por várias alunas, quando trabalhamos, em diferentes dinâmicas, a percepção de semelhanças e diferenças na turma. Chamou a atenção, nessas atividades, o fato de os grupos terem enfatizado os aspectos de igualdade nos relatos apresenta- 
dos em plenária. Os seguintes comentários chegaram a ser registrados: "É fácil identificar as igualdades. As diferenças são mais complicadas"; "A diferença é difícil de colocar em palavras"; "As igualdades agregam mais". Além disso, falouse também que as diferenças entre as alunas eram mais numerosas do que as semelhanças, apesar da maior facilidade de verbalizar estas últimas. Entretanto, mais tarde, nesse mesmo dia, presenciamos uma virtual unanimidade em torno da afirmação e da condenação da pretensão homogeneizadora da escola em face das muitas diferenças que ali se encontram e desencontram.

Esse quadro reafirma para o grupo a pertinência da discussão sobre as diferenças no campo da Didática: sua presença e relevância no cotidiano escolar não costumam ser negadas - entretanto, o que fazer, a partir desse reconhecimento, é ainda uma questão em aberto.

A diferença é "difícil", "não agrega", é "conflito potencial". Por sua vez, o conflito tende a assumir um aspecto negativo, e, paralelamente ao reconhecimento da inevitabilidade das muitas diferenças na escola, sobrevivem o desejo e o mito da homogeneidade e da suposta harmonia que esta traria. A Didática que assume a perspectiva multi/intercultural está chamada a enfrentar essa discussão e pensar alternativas no sentido de evidenciar e promover a produtividade da sala de aula heterogênea, além de contribuir para a desconstrução desses mitos. Concorrerão, para tanto, contribuições teóricas já consolidadas em outros campos - como, por exemplo, o da chamada filosofia da diferença -, mas também práticas didáticas concebidas nessa perspectiva. Além da postura dialógica mencionada, utilizamos uma estratégia simples, porém que julgamos eficaz no sentido de favorecer a troca interpares na turma: na maior parte das vezes, os grupos de trabalho foram formados aleatoriamente. Pretendíamos, desse modo, criar situações de convívio entre diferentes que, provavelmente, não se aproximariam sem tal iniciativa. A eficácia de tal medida não pôde ser avaliada com maior precisão, mas os registros de observação em geral apontaram mais para dificuldades do que para realizações nesse sentido. Permanece o desafio para a perspectiva multi/intercultural na educação, uma vez que insistimos no diálogo, na troca, em avançar para além da tolerância. Entretanto, concordamos com Skliar, quando argumenta que:

Em toda figura do outro existiria um outro próximo, isto é, um outro que não sou eu, um outro que é diferente de mim, mas que eu posso ver, materializar, 
compreender e, inclusive, assimilar; também existiria um outro radicalmente diferente de mim, um outro que é (in)assimilável, incompreensível e ainda mais e, sobretudo, impensável. $\bigcirc$ que o Ocidente tem feito com essa dúplice figura do outro, não é mais do que uma tentativa de reduzir o outro radical a um outro próximo. E mais do que reduzi-lo, do que se trata é de apagar, extinguir e acabar com toda diferença radical. (2004, p.73)

As dificuldades aqui assinaladas não são mais do que a modesta ponta visível de um iceberg de obstáculos com que se defronta essa proposta, não se restringindo ao universo educacional. E mesmo nesse universo, a resistência à interação com o outro tampouco constitui a única questão colocada pela proposta de articulação da perspectiva da igualdade com a da diferença.

\section{Igualdade e diferença}

Hortênsia é uma aluna que já atua como professora em uma escola reconhecida e tem em casa uma filha ainda bebê. Sua participação se destaca pela pertinência das colocações que faz, embora sua produção semanal escrita seja irregular no que se refere ao cumprimento dos prazos acordados. Os prazos, nesse caso, têm um significado pedagógico claro: sem ler os textos e fazer os trabalhos solicitados, a participação nos momentos de discussão dessas produções fica, de algum modo, comprometida. Ainda assim, como a leitura dos textos e a elaboração dos trabalhos constituem, em si mesmas, importantes situações de aprendizagem, as datas para o seu recebimento foram flexíveis. Entretanto, tal flexibilidade teria limites: em algum momento - e esse momento não foi definido pelo grupo da pesquisa - as alunas precisariam de uma nota final, de uma decisão quanto à sua aprovação ou reprovação. Diante dessa contingência, a professora coordenadora do curso anunciou, várias vezes, um prazo derradeiro para a entrega dos trabalhos pendentes. No último dia de aula, já passada essa data final, Hortênsia e quatro outras alunas trouxeram produções atrasadas. A professora já devolvia os últimos trabalhos corrigidos e manteve o combinado que determinava que as produções retardatárias não seriam aceitas. $\bigcirc$ período para entrega das médias finais esgotava-se e a professora não teria condições de corrigi-los a tempo. Algumas alunas aceitaram a decisão, mas Hortênsia se desesperou. Chorou, revoltou-se, acusou. Fomos con- 
versar. Dizia que tudo o que havia sido defendido no curso "caía por terra" diante da nossa intransigência. Lembrou suas dificuldades, problemas de saúde, falta de tempo, e mencionou, com muita mágoa, os sacrifícios que havia feito para dar conta das tarefas pendentes, em um contexto de final de ano letivo. Falou ainda que seu trabalho individual, feito naquele dia em sala de aula e com importante peso na avaliação, havia sido afetado por seu estado emocional, abalado pelo ocorrido. Temia por uma reprovação, o que traria sérias conseqüências para a sua vida pessoal e profissional. Sabíamos que tal hipótese não existia de fato, uma vez que sua atuação não seria avaliada apenas por essas produções, mas, sem dúvida, a situação nos mobilizou.

Os contra-argumentos que utilizamos foram vários, mas um deles pode ser considerado emblemático da tensão que surge da articulação igualdadediferença na educação. Entendíamos que se abríssemos uma exceção para aquela aluna, teríamos de receber todos os outros trabalhos, o que não era possível. Estávamos seguindo a tradicional lógica homogeneizadora da escola? Ou nos deparávamos com limites objetivos de possibilidade de reconhecimento das diferenças em um trabalho coletivo?

Em outra situação do curso, uma das pesquisadoras fez questionamentos, nos seus registros, acerca da sexta oficina: "Como olhamos esse grupo? Nosso olhar homogeneizou o grupo? Se não for assim, por que esperamos que todos acompanhem as oficinas da mesma forma?". E a questão se reformula, mas a tensão permanece: o reconhecimento da diferença pode implicar desigualdade (no caso, desigualdade no aproveitamento pedagógico do trabalho da oficina)?

Tínhamos claro que: "Não se deve contrapor igualdade e diferença. De fato, a igualdade não está oposta à diferença, e sim à desigualdade, e diferença não se opõe à igualdade e sim à padronização, à produção em série, à uniformidade, a sempre o 'mesmo', à 'mesmice'" (Candau, 2005, p. I 8).

No primeiro caso, medidas as conseqüências - isto é, considerando-se que não havia a possibilidade de reprovação da aluna - mantivemos uma exigência, em certa medida, padronizada, uma vez que houve uma mesma datalimite para todas as alunas, independentemente das especificidades dos processos de ensino-aprendizagem que viviam. Trabalhávamos com prazos definidos, não por razões pedagógicas, mas sim por exigências institucionais, como tantas outras que existem no dia-a-dia da educação formal. $O$ coletivo não se organiza sem regras; regras não cumprem sua função organizacional se a adesão dos envolvidos está condicionada ao seu arbítrio individual e circuns- 
tante. Podemos nos opor e trabalhar pela mudança de regras das quais discordamos; contudo, manipulá-las arbitrariamente, ainda que a motivação seja a intenção do respeito à diferença, pode ser bastante problemático. É importante ressaltar que se tratava de um curso de nível superior, que proporcionaria certificação para o exercício profissional do magistério, mediante o cumprimento de determinadas exigências. Nessa circunstância, avaliamos que o individual deveria ter acompanhado o coletivo. Como lembra Gimeno Sacristán (2002, p. 17): "Essa condição e aspiração à individualidade, com seus conflitos inevitáveis, são compatíveis com a realidade de possuirmos traços comuns com os demais, por dispormos de alguma condição que nos torne semelhantes a eles ou por desejarmos certos ideais compartilhados".

Compartilhávamos uma mesma estrutura educacional, objetivos e atividades pedagógicas em uma disciplina. Atentar para as questões da diferença não implica radicalizar a individualização do ensino, o que não é viável, tampouco desejável em termos educativos. Retomando Gimeno Sacristán: "a escola é o primeiro espaço público vital para os indivíduos onde a vida comum obriga a restringir a contemplação das características individuais dos sujeitos" (p. I 8). No entanto, discordamos desse autor, quando prossegue em sua reflexão, argumentando que o "problema é de equilíbrio", por percebermos os contextos educacionais como situações marcadamente complexas e conflitivas. Essas situações se caracterizam, entre outros aspectos, pelos vínculos de tensão que articulam seus elementos componentes. A noção de tensão evoca uma relação dialética, que não se resolve, não se estabiliza, a não ser transitoriamente. A cada nova contingência em que o reconhecimento das diferenças se choca com os direitos de igualdade, no âmbito educacional, as razões de cada pólo de tensão estarão em novo confronto e definirão caminhos também contingentes, não necessariamente de equilíbrio entre tais pólos. À Didática que incorpora a crítica multi/intercultural não resta alternativa senão assumir os riscos da desconstrução e/ou reconstrução permanentes das respostas às muitas situações de tensão que reconhece na prática educativa, inclusive das respostas às questões da articulação igualdade-diferença.

\section{Desconstrução e resistência}

A experiência do curso evidenciou ainda a complexidade da proposta de desconstrução que assumimos. A dificuldade que percebemos, por parte das 
alunas, na discussão de temas que consideramos centrais para a perspectiva multi/intercultural pareceu sinalizar a necessidade de insistir na busca de alternativas didáticas que potencializem esses novos estudos, mas também expôs a pertinência de incluí-los nos cursos de Didática. Essa dificuldade também denunciava a ausência, ou pelo menos a fragilidade, da abordagem de tais temáticas pelas outras disciplinas que compõem o currículo de formação das professoras. Entre outras questões, surpreendeu o grupo a pouca familiaridade da turma, em termos gerais, com o questionamento da categoria "universal", quando pensamos valores e saberes na escola, do caráter constitutivo e não meramente representativo da linguagem, e também da problemática étnico-racial na educação.

Como é sabido, a escola que conhecemos nasce com a modernidade, no momento da afirmação da categoria universal no pensamento e, até certo ponto, nas práticas políticas européias. Antes de qualquer argumento crítico, cumpre ressaltar o caráter inédito de tal noção naquele contexto histórico. Precedidas pelos valores de sociedades teocráticas e/ou estruturadas segundo privilégios de nascimento, a idéia de direitos universais e a própria noção de humanidade apresentavam-se, à época, com um teor revolucionário que ainda se faz presente em um mundo partido entre proprietários e despossuídos. A perspectiva multi/intercultural valoriza essa dimensão libertadora, porém questiona a naturalização de uma universalidade com freqüência restrita às esferas formais da vida social e marcada por um forte eurocentrismo. Critica com igual ênfase o relativismo radical que legitima quaisquer valores e saberes, sob a alegação de respeito a todos os universos culturais.

Nessa perspectiva, consideramos importante assumirmos o desafio de trabalhar a tensão dialética entre universalismo e relativismo, entre igualdade e diferença. Não estaremos chamados a relativizar o universalismo, afirmando seu caráter histórico e dinâmico, e, ao mesmo tempo, a relativizar o relativismo, afirmando o seu caráter não absoluto, atento aos 'meta-valores', aos conteúdos transculturais, historicamente construídos? (Candau, 2000, p.83)

Foi o que buscamos discutir em nosso curso, em especial na oitava oficina, quando abordamos mais diretamente a questão dos valores na educação escolar. Explicitar a dimensão histórica de tais valores não implica recusá-los. 
Implica, sim, o favorecimento da construção de uma postura crítica que rejeita a naturalização do certo e do errado nas sociedades, mas que também podese abrir para a negociação de outros referentes comuns, mínimos e provisórios, que viabilizem o convívio produtivo das diferenças.

Percebemos, entretanto, que não se trata de discussão trivial. A noção do universal se nos apresentou sólida e consistente entre as alunas, de fato, um desafio para a perspectiva em que nos propusemos a trabalhar.

Do mesmo modo, o questionamento da linguagem - um dos focos permanentes da nossa atuação - esbarrou na rigidez da sua naturalização. Com freqüência, e não apenas nos espaços educacionais, a preocupação com a linguagem é tida como exagero do "politicamente correto" - um movimento político que nasce sério nos EUA, mas que nos chega apenas em sua versão caricata. Tendemos a acreditar que nunca queremos dizer o que dizemos. Parece estar presente, nessa postura, um traço marcante das tradições políticoculturais brasileiras: a negação do conflito. Apesar de reconhecermos que a preocupação com o chamado politicamente correto pode tender à censura arbitrária dos que se supõem autorizados a classificar o que é ou não admissível na linguagem, não podemos prescindir dessa discussão em um curso de formação de professoras do século $X X I$, inclusive para ponderarmos sobre seus limites. Consideramos, assim, que a onipresença da linguagem na vida social e seu relativo poder de constituição da realidade tornam este um debate central para a Didática ressignificada pela perspectiva multi/intercultural.

As educadoras precisam examinar criticamente o desenvolvimento de discursos e práticas pedagógicas que demonizam os Outros que são diferentes (ao transformá-los em ausentes e perturbados/as). O multiculturalismo crítico chama séria atenção para os sistemas de significados dominantes disponíveis aos estudantes e educadoras e que em sua maioria estão ideologicamente costurados no tecido do patriarcado e imperialismo ocidentais. Ele desafia os sistemas de significados e impõem atributos ao outro sob a orientação de significantes e metáforas soberanos. (McLaren, 2000, p. 135)

É ainda esse autor, nessa mesma publicação, quem nos lembra da importância de "desconstruir a etnicidade branca", outro desafio cuja pertinência foi confirmada em nossa experiência. 
Já na primeira oficina, o silêncio, por parte das alunas, acerca das questões étnico-raciais na educação foi observado por todas as pesquisadoras. Se no contexto de atuação de McLaren, isto é, nos Estados Unidos, tal questão se coloca para as/os educadoras/es, no Brasil, onde o racismo historicamente se camuflou no mito da democracia racial, apresentando-se fugidio e diluído em práticas e palavras mais ou menos sutis, porém de efeitos sempre devastadores para as/os portadoras/os das marcas discriminadas, essa temática reveste-se de ainda maior urgência e complexidade. A importância do tema tem sido cotidianamente trazida a público pelos meios de comunicação, na forma da divulgação dos diversos estudos estatísticos que atestam que tal diferença tem, historicamente, implicado graves desigualdades sociais, ou nos debates sobre as ações afirmativas, especialmente sobre as cotas raciais para ingresso nas universidades públicas. Sua urgência pode ser exemplificada por esse silêncio que percebemos já no início do curso e que, aparentemente, pouco se alterou durante o seu transcorrer, apesar dos nossos esforços nesse sentido.

\section{DIDÁTICA E PERSPECTIVA MULTI/INTERCULTURAL: UMA PROPOSTA EM CONSTRUÇÃO}

Não sem razão esse título nomeou o curso aqui discutido. Reconhecemos que estamos propondo um caminho que apenas começa a ser trilhado, um caminho ainda em construção. No desenvolvimento dessa experiência, confrontamo-nos não apenas com os desafios aqui brevemente discutidos, mas também com vários outros, de ordem operacional e/ou teórica.

Ficaram claras, por exemplo, as limitações das possibilidades de atuação de somente uma disciplina no processo de formação de professoras, no sentido das desestabilizações pretendidas. Além disso, no desenvolvimento da proposta, tivemos de continuamente buscar articulações com os condicionamentos institucionais, que definem datas, ritmos e modos que nem sempre se justificam pedagogicamente. Tivemos também de negociar permanentemente com o "ofício de aluno" (Perrenoud, 1997). Lutamos contra o tempo, que rivalizava nossas pretensões dialógicas e favorecia a imposição de uma narrativa única. No entanto, os diversos e complexos desafios com que nos deparamos nos reafirmaram na direção do caminho que estamos coletivamente construindo. 


\section{REFERÊNCIAS BIBLIOGRÁFICAS}

BARBIER, R. A Pesquisa-ação. Brasília: Liber Livro, 2004.

BARREIROS, C. H. Dialogando com Peter McLaren: em busca de uma prática pedagógica multicultural e crítica. In: CANDAU, Vera M. (org.) Cultura(s) e educação: entre o crítico e o pós-crítico. Rio de Janeiro: DP \& A, 2005. p.95- I 14.

CANDAU, V. M. O Currículo entre o relativismo e o universalismo: dialogando com JeanClaude Forquin. Educação \& Sociedade, Campinas, v.21, n.73, p.79-83, dez. 2000

Sociedade multicultural e educação; tensões e desafios. In: CANDAU, V. M. (org.). Cultura(s) e educação: entre o crítico e o pós-crítico. Rio de Janeiro: DP \& A, 2005. p. 13-37.

Vozes, 2002.

(org.) Sociedade, educação e cultura(s): questões e propostas. Petrópolis:

CANDAU, V. M. et al. Oficinas pedagógicas de direitos humanos. Rio de Janeiro: Vozes, 2000.

GIMENO SACRISTÁN, J. A Construção do discurso sobre a diversidade e suas práticas. In: ALCUDIA, R. et al. Atenção à diversidade. Porto Alegre: Artmed, 2002. p. I3-37.

McLAREN, P. Multiculturalismo crítico. São Paulo: Cortez, 2000.

PÉREZ GÓMEZ, A. I. A Cultura escolar na sociedade neoliberal. Porto Alegre: Artmed, 200। .

PERRENOUD, P. 10 Novas competências para ensinar: convite à viagem. Porto Alegre: ArtMed, 2000. Conceber e fazer evoluir os dispositivos de diferenciação pedagógica, p.55-77.

O Ofício de aluno e sentido do trabalho escolar. Porto: Porto Editora, 1997.

SKLIAR, C. A Materialidade da morte e o eufemismo da tolerância: duas faces, dentre as milhões de faces, desse momento (humano) chamado racismo. In: GALLO, S.; SOUZA, R. M. (orgs.) Educação do preconceito: ensaios sobre poder e resistência. Campinas: Alínea, 2004. p.69-90.

STOER, S.; CORTESÃO, L. "Levantando a pedra": da pedagogia inter/multicultural às políticas educativas numa época de transnacionalização. Porto: Afrontamento, 1999. A Interculturalidade e a educação escolar: dispositivos pedagógicos e a construção da ponte entre culturas, p. $51-72$.

THIOLLENT, M. Metodologia da pesquisa-ação. São Paulo: Cortez, 1985.

Recebido em: julho 2006

Aprovado para publicação em: novembro 2006 